\title{
Production Management and Quality Assurance for the Fabrication of the In-Vessel Components of the Stellarator Wendelstein 7-X
}

\author{
C. Li*, J. Boscary, N. Dekorsy, P. Junghanns, B. Mendelevitch, A. Peacock, H. Pirsch, \\ O. Sellmeier, J. Springer, R. Stadler, B. Streibl
}

Max Planck Institute for Plasma Physics, Boltzmannstr. 2, 85748 Garching, Germany

The In-Vessel Components (IVC) of the stellarator Wendelstein 7-X consist of the divertor components and the first wall $(\mathrm{FW})$ with their internal water cooling supply and a set of diagnostics. Due to the significant amount of different components, including many variants, a tool called Production Managing System (PMS) has been developed to organize the fabrication and the associated quality assurance. The PMS works by building a database containing the basic parts and assembly data, manufacturing and quality control plans, and available machine capacity. The creation of this database is based mainly on the parts lists, the manufacturing drawings, and details of the working flow organization. As a consequence of the learning process and technical adjustments during the design and manufacturing phase, the database needed to be permanently updated. Therefore an interface tool to optimize the data preparation has been developed. PMS has been demonstrated to be an efficient tool to support the IVC production activities providing reliable planning estimates, easily adaptable to problems encountered during the fabrication and provided a basis for the integration of quality assurance requirements .

Keywords: W7-X, in-vessel components, quality assurance, manufacturing organization

\section{Introduction}

Wendelstein 7-X (W7-X) is a highly complex stellarator fusion experiment which is currently being built at the Max Planck Institute for Plasma Physics (IPP), Greifswald. In-Vessel Components (IVC) of W7-X are designed to be actively watercooled to allow long pulse operation. According to the structure of the plasma boundary, the IVC are modularly designed based on 5 field periods $[1,2$, $3]$.

The IVC are designed at IPP and mainly manufactured at the ITZ (Integriertes TechnikZentrum) workshops of IPP Garching, and then delivered to IPP Greifswald. With more than 2500 components, IVC are built from over 700000 parts. To organize the fabrication and the associated quality assurance, the use of an enterprise resource managing tool was needed. On the market there are several providers of such tools, e.g. SAP, Eigner etc. [4, 5]. Unfortunately, those tools normally require great efforts to prepare the manufacturing data and the flexibility to modify the data after it has been introduced in the system is limited. Since the IVC are manufactured and designed concurrently in a complex project the ability to react to changes was needed. The Production Managing System (PMS) [6] developed by the University of Reutlingen allows for flexibility and has therefore been used from the beginning of IVC manufacturing. Due to the easy data installation, flexibility and simple maintenance, this tool is particularly suitable for a small manufacturing enterprise. These advantages of PMS were used frequently as technical adjustments during the design and manufacturing phase occurred relatively often $[7,8,9,10]$.

In addition the need to integrate the quality requirements into the manufacturing from the beginning was an essential feature of this tool.

In order to perform the manufacturing planning and the quality assurance by means of PMS, a database including the following data had to be built:

- $\quad$ Parts and assembly data - containing part identification, drawing number, weight, used materials, stock location and sourcing type;

- Plan data - containing plan identification, parts lists, working and quality assurance plans;

- Working resource data - containing resource identification and capacity.

During the fabrication of the IVC, the drawings were progressively fed to the ITZ workshop. Due to technical adjustments, the released design data occasionally changed. To adapt to this continuous process of data addition and modification, a special interface was developed and included in the PMS code to take into account this kind of modification.

\section{Part identification and classification}

For a database the definition of the parts identification (part-id) plays an important role. Because the part-id is used as a part label 
throughout the whole production process, it should be short and semantically rich. The defined part-id consists of three letters labeled " $B$ " and three digits labeled "Z": BB-BZZZ. As IVC are modularly built, the three letters " $\mathrm{B}$ " are classified as follows:

- The first letter classifies the part type. There are only four letters used here: E for end product (assembled part to be delivered to IPP Greifswald), $\mathrm{G}$ for assembly, $\mathrm{T}$ for part and $\mathrm{R}$ for semifinished products.

- The second letter classifies the IVC component: e.g. T for Target, B for Baffle, $\mathrm{H}$ for heat shield, etc.

- The third letter classifies the part kind: e.g. A for screw, R for tube, $\mathrm{Z}$ for graphite tile, etc.

The second and third letters " $\mathrm{B}$ " of the part-id used for the classification of parts refer to the first use of a part or an assembly design. When the same part is used in different components, the part-id is not changed. For the part numbering three digits "Z" are used for identification but in rare cases four digits are needed, for example, when the number of parts is $\geq 1000$.

In order to enable further search possibilities and better filter function of parts in the database, a classification schema: B-B-B-YY-C-C has been defined. This classification provides significant benefits in organizing the IVC manufacturing, since it additionally includes the sourcing type and part material.

The classification schema for each part or assembly is automatically generated during the data preparation phase to monitor the fabrication of the parts. In the classification, the first three letters "B" come from the part-id. While the first letter " $C$ " codes the sourcing type ( $\mathrm{E}$ for in-house and $\mathrm{F}$ for external production), the second letter " $\mathrm{C}$ " indicates the part material. If a part or an assembly is not manufactured from one material, a letter such as $\mathrm{X}$ (a part is made of different materials such as copper and steel for example) is used. Between the five letters, the classification schema has two digits "Y" which are used to code the component number.

\section{Data installation}

The operation of PMS requires as a first step the generation of a database. In the database, the main manufacturing master data are the working resource data and the parts data. The working resource data describe the available capacities in ITZ. The parts data accumulate continuously as design data is delivered from the drawing office. To limit the effort needed to install this data, an interface managed with Excel ${ }^{\circledR}$ macros has been developed to transfer the parts data directly from the component parts lists as a PMS-compatible input (see "Interface" in Fig. 1). This feature meant that the use of PMS had to be introduced into the design activities but also meant that design data could also be transferred to PMS, a useful feature for keeping track of material issue.

Fig. 1 shows the data installation route for the PMS database. The initial parts lists, containing the drawing numbers and weight, are implemented with the introduction of additional information: sourcing type and material needs per in-house manufactured part (sourcing type E or F ). The resource demand, work plan and organization, the inspections required for the quality management of the parts are also taken into account. The data import into the PMS database consists in the creation of tables which contain parts data, plan data with assignable plan-id, part structure and working plan. After the implementation, the data are further configured using the PMS functions to define the relationships between the data associated to each part and to generate some additional data fields.

\begin{tabular}{|c|}
\hline $\begin{array}{l}\text { Design and development } \\
\text { - Parts lists } \\
\text { - Manufacturing drawings }\end{array}$ \\
\hline$\sqrt{2}$ \\
\hline $\begin{array}{l}\text { Process planning } \\
\text { - Sourcing types } \\
\text { - Work und quality control planning }\end{array}$ \\
\hline$\sqrt{2}$ \\
\hline $\begin{array}{l}\quad \text { Interface } \\
\text { - Creation of PMS-compatible Data from parts lists } \\
\text { - } \quad \text { Allocation of work und quality control planning for } \\
\text { - Creation of import-data for PMS }\end{array}$ \\
\hline$\sqrt{2}$ \\
\hline \begin{tabular}{l}
\multicolumn{1}{c}{ PMS } \\
- $\quad$ Parts and assemblies data \\
- $\quad$ Porking machine capacity \\
- $\quad$ Sourcing and stock data
\end{tabular} \\
\hline
\end{tabular}

Fig. 1 Parts and assemblies data flow into the PMS database.

The solution with data-import provides significant advantages in the data preparation and variant management for the IVC manufacturing, as it permits to optimize the interaction of the IVC design and manufacturing process in the most flexible way and to provide a fast and flexible overview about the production. This data installation can be executed with minimal efforts.

\section{Quality inspection document}

Inspection, i.e. dimensional measurement, pressure drop measurement, etc. of the manufactured components are an integral part of the IVC production. The results of these controls determine the next step in the manufacturing sequence. Problems encountered during the fabrication must be addressed as soon as possible in order to minimize delays, the un-productive use of resources and so the information used can be used 
to adapt the planning and be feedback into the design to avoid similar issues happening in the future. During manufacturing of the IVC the fabrication and assembly activities are carefully planned and qualified. Their quality inspections are documented in order to ensure that all inspections are carried out as planned and that the required manufacturing quality is achieved. The quality documentation for the most important tests and measurements has broadly three parts:

- Document header data which contain the part and important code data used in the fabrication.

- Sequence of planned inspections.

- Detailed quality inspection table which contains all essential work and test steps with the defined acceptance criterion.

The layout of the inspection document provides significant advantages in the quality assurance, because

- All of the inspections and their results are summarized in one table and the detailed inspection document can be accessed directly,

- The empty inspection protocol is created from the defined draft according to the assembly type and the document header data can be generated from the PMS database using integrated Word $\AA$ macros.

This organization provides a real time monitoring of the inspections of the components and their results, provides a documentation of the possible deviations and allows a fast reaction to find solutions.

Among the IVC, the baffles and heat shields, for example, have different functions but they have a similar assembly structure. In their fabrication the same Quality Control Plan (QCP), which serves to define the detailed inspections, is used. In the IVC manufacturing there are more than 15 different types of QCPs in the form of a Word $\AA$ document. Each Word $\AA$ file is identified with a document number and implemented in the PMS QCP database.

\section{Application in the manufacturing}

To support the IVC activities, PMS plays a variety of roles, for example: data managing and searching, inventory control, order transaction, cost calculations and product planning. In this section two typical applications of PMS in the IVC manufacturing, production planning and quality assurance associated with the data managing will be described.

\section{Production planning}

Production planning is a core application of PMS in the IVC manufacturing. As the whole W7$\mathrm{X}$ project priorities and their associated milestones are pre-defined and the resourcing at the ITZ workshops is limited, the meeting of deadlines and the prioritization of different components meant that this tool was vital to define and optimise the manufacturing planning.

According to the production breakdown structure [11, 12], each work order for the IVC was defined in PMS. Fig. 2 shows the flow chart of production planning to achieve the manufacturing schedule. For each work order, PMS calculates all of the required manufacturing sub-orders and sourcing orders, provides a schedule taking automatically into account data on available stock materials and the available production capacity. In the case of an unacceptable process time, the process can be repeatedly iterated with modified parameters to eliminate bottlenecks.

In the case of bottlenecks which lead to unexpectedly long process times due to specific machine capacity shortages, two main actions are possible:

- Re-definition of priorities. All of the work orders at a machine during the period of interest can be re-assessed and optimised.

- Use of new resources. This solution is implemented when insufficient resources are available internally and a work order is placed to an industry co-operation partner. PMS also takes into account the increased administrative overhead of placing external contracts.

Both actions try to reach compatibility between resources and milestones.

In addition to defining the manufacturing schedule, PMS also schedules the material procurement and demand of resources. Based on the modular grouping, the whole material and resourcing requirements can be derived from already fabricated components or prototypes. This increases the planning reliability during the early manufacturing phase. The delivery of steel materials generally needs significant time as only ESR (Electroslag remelting)-materials are used.

\section{Quality assurance}

During the manufacturing of the IVC, each component is checked and documented according to the QCP which lists all of the essential inspections with their document codes. In the early manufacturing phase, the QCP are created per type and released by the responsible people such as, the technical responsible officers, design department, assembly organization, QM. During the inspections each step must be signed by the responsible person and the continuation of the manufacturing work is 


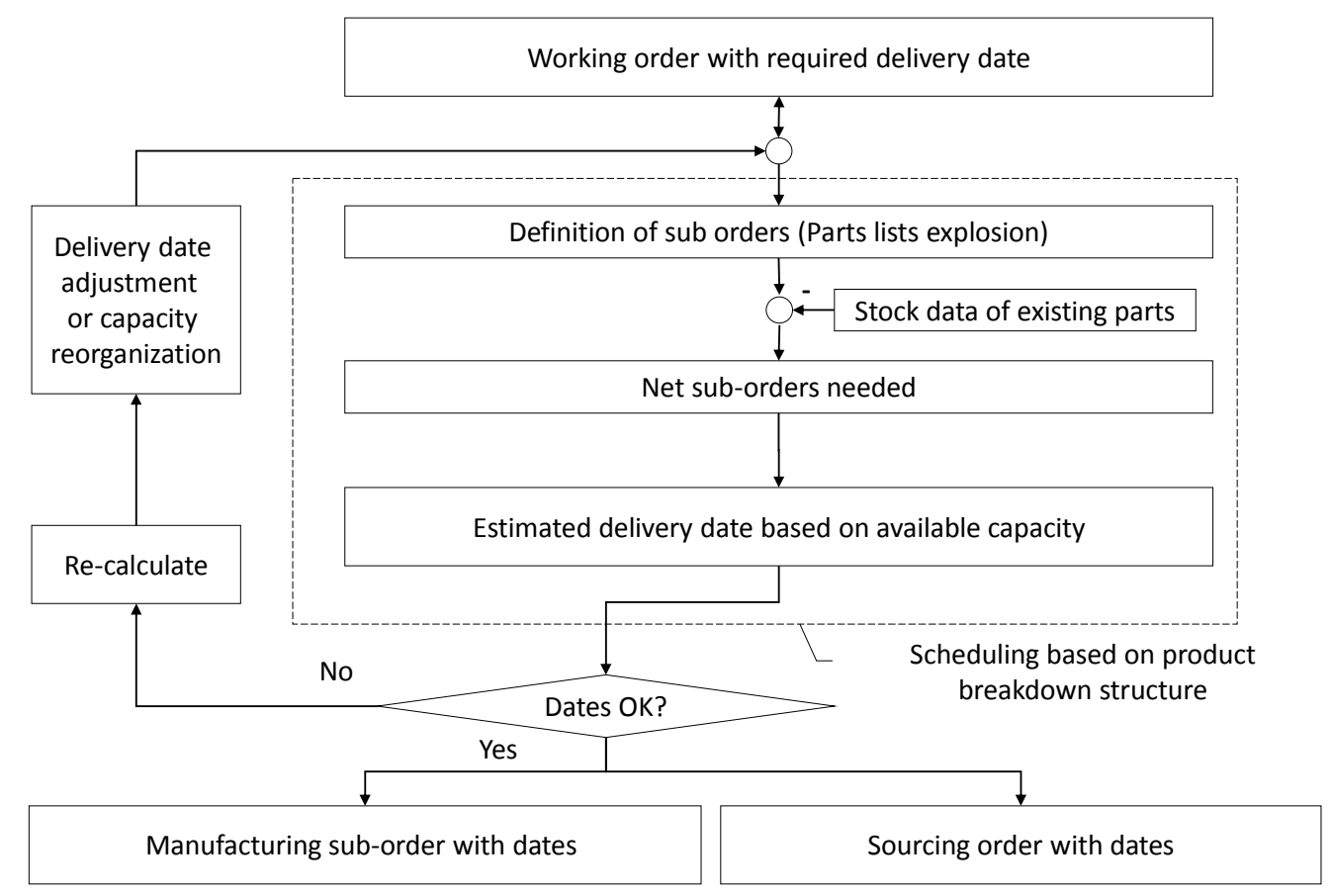

Fig. 2 Flow chart of production planning using PMS to optimize the manufacturing schedule. If the manufacturing dates are not satisfied after the iteration process, alternative solutions such as searching for new resourcing outside etc. are needed.

Per part

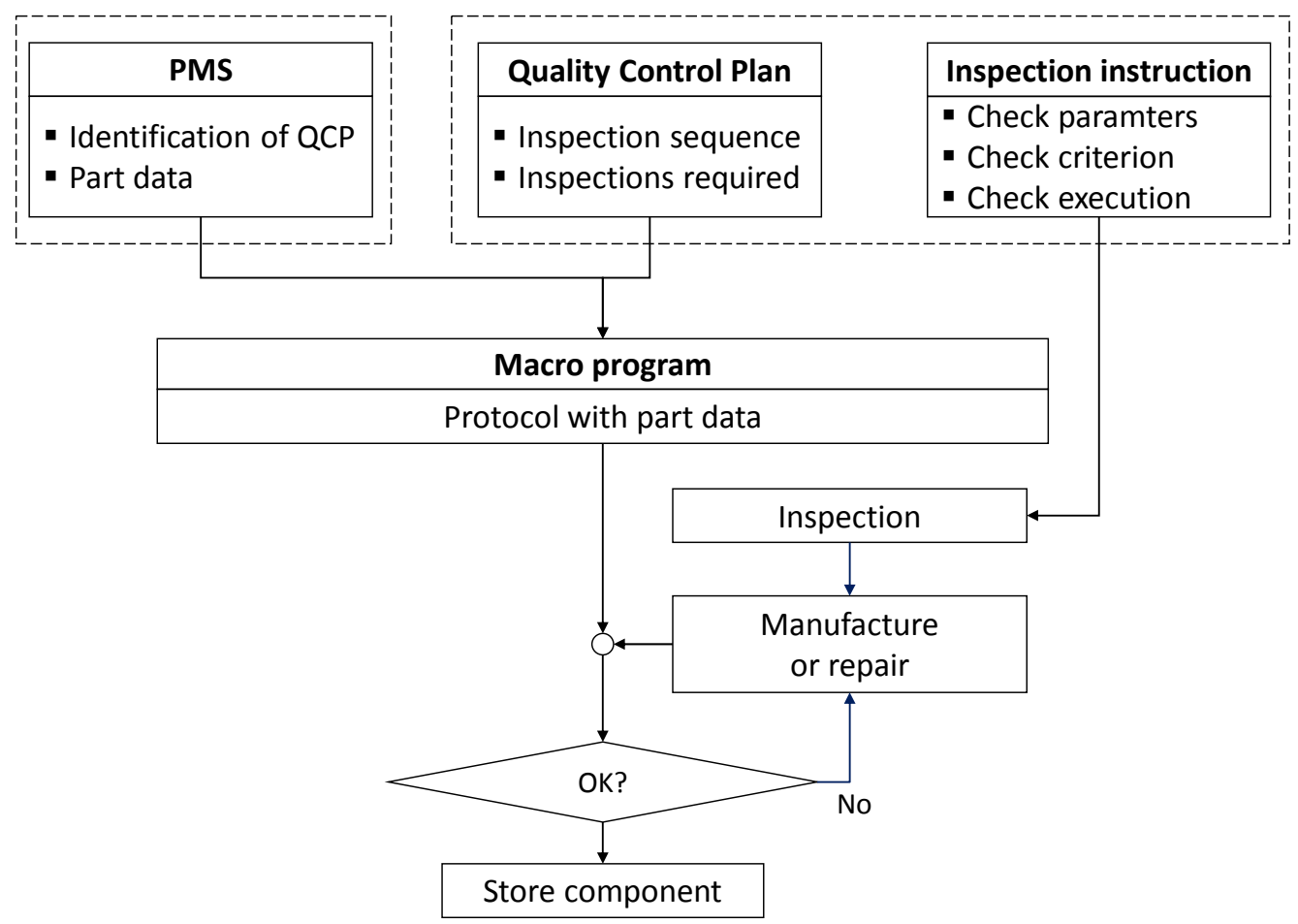

Fig. 3 Flow chart of quality assurance. The part data for the inspection protocol can be written directly from the PMS database with the help of a Word $\AA$ macro program. The quality inspection will be carried out according to the appropriate inspection instruction 
only allowed after the successful execution of the preceding step. For more details about the quality inspection, see $[7,13]$.

The application of PMS in the quality assurance focuses mainly on the data supply to the quality inspection document. Fig. 3 shows the flow chart of quality assurance associated with the data management. PMS has no implemented function for selecting a Word $\AA$-file. A special macro program is required in this case initiated by the data of the sub-orders defined during product planning. The part data and the document number are connected with the sub-order. With help of the macro program the right quality inspection document for the right part can be thus generated.

As described in chapter 4, the quality document contains mainly tables in which the inspection results are detailed. In the quality inspection, the inspection instruction is required, in order to ensure that the inspection is carried out as defined. In the inspection instruction, the details of the inspection parameters and acceptance criterion are defined. After successful quality control, the component can be stored or passed to the next manufacturing step.

\section{Conclusion}

In the IVC activities PMS code was chosen to organize and control the manufacturing processes. The implemented numbering scheme for part identification and classification was sufficient for handling the manufacturing process. The versatile interface tool for data acquisition permitted the management of a continuously growing number of components and variants together with their design updates. The product planning, scheduling and demand calculation, the main modules of PMS code allowed a new working order to be automatically placed and interleaved with the running manufacturing process. Further useful PMS features are the data managing of quality assurance and the coordination of the required information flow over all instances of the manufacturing process.

Using the PMS system allowed:

- a system to be developed for the organization and control of the IVC manufacture.

- $\quad$ all parts to be delivered for Assembly with the necessary documentation.

- a material database to be developed for the IVC components, used for safety assessments and material inventory estimates.

- reliable planning and resource data to be available to the project for the IVC components.

\section{References}

[1] S. Benhard, J. Boscary, H. Greuner, P. Grigull, J. Kißlinger, C. Li et.al., Manufacturing of the Wendelstein 7-X divertor and wall protection, Fus. Eng. Design 75-79 (2005) 463-468

[2] R. Stadler, A. Vorköper, J. Boscary, A. Cardella, F. Hurd, Ch. Li et al., The in-vessel components of the experiment Wendelstein 7-X, Fus. Eng. Design 84 (2009) 305-308

[3] R. Stadler, A. Vorköper, J. Boscary, Ch. Li, B. Mendelevitch, A. Peacock et al., Challenges in the Realization of the In-Vessel-Components of Wendelstein 7-X, Fus. Eng. Design 88 (2013) 16861689

[4] J. Balla et al., Production Planning with SAP APOPP/DS, SAP PRESS; 1 edition (October 28, 2006), ISBN: 9781592291137

[5] M. Eigner, Product Life Cycle Management, Springer-Verlag GmbH, 10/2008 ISBN: 9783540443735

[6] F. Wieneke, Produktionsmanagement, Verlag Europe-Lehrmittel, Vollmer GmbH \&Co., 2004 ISBN: 3-8085-5311-1

[7] B. Mendelevitch, A. Vorköper, J. Boscary, Ch. Li, N. Dekorsy, A. Peacock et al., Lessons learned from the design and fabrication of the baffles and heat shields of Wendelstein 7-X, Fus. Eng. Design 88 (2013) 1660-1663

[8] J. Boscary, R. Stadler, A. Peacock, F. Hurd, A. Vorköper, B. Mendelevitch et al., Design and technological solutions for the plasma facing components of Wendelstein 7-X, Fus. Eng. Design 86 (2011) 572-575

[9] A. Peacock, A. Girlinger, A. Vorköper, J. Boscary, H. Greuner, F. Hurd et al., The procurement and testing of the stainless steel in-vessel panels of the Wendelstein 7-X stellarator, Fus. Eng. Design 86 (2011) 1706-1709.

[10] B. Mendelevitch, A. Vorköper, J. Boscary, A. Cardella, F. Hurd, Ch. Li et al., Design analysis and manufacturing of the cooling lines of the in-vessel components of Wendelstein 7-X, Fus. Eng. Design 86 (2011) 1669-1672.

[11] F.J. O'Donnell et al., Product structuring in a small manufacturing enterprise, Elsevier Computer in Industry 31 (1996) 281-292

[12] REFA, Methodenlehre der Planung und Steuerung, Hanser Fachbuchverlag (1991) ISBN: 9783446142459

[13] R. Vilbrandt, Quality assurance during assembly of Wendelstein 7-X, Fus. Eng. Design 86 (2011) 656658 